\title{
TWO DIMENSIONAL ECHOCARDIOGRAPHY ESTIMATES OF FETAL VENTRICULAR MASS THROUGHOUT GESTATION
}

Short title: Two dimensional echocardiography \& fetal cardiac mass

Christina YL Aye $e^{\mathrm{a}, \mathrm{b}}$, BMBCh, MA (Oxon), MRCOG; Adam James Lewandowski ${ }^{\mathrm{a}}$, PhD; Eric O Ohuma ${ }^{\mathrm{c}}$, DPhil; Ross Upton ${ }^{\mathrm{a}}$; Alice Packham ${ }^{\mathrm{a}}$, BA(Hons); Yvonne Kenworthy ${ }^{\mathrm{a}}$, BSc(Hons); Fenella Roseman ${ }^{\mathrm{b}}$; Tess Norris ${ }^{\mathrm{b}}$; Malid Molloholli ${ }^{\mathrm{b}}$, MRCOG; Sikolia Wanyonyi ${ }^{\mathrm{b}}$, MBChB, MMed, MRCOG; Aris T Papageorghiou ${ }^{\mathrm{b}}$, MBChB, FRCOG; Paul Leeson ${ }^{\mathrm{a}}$, PhD, FRCP

${ }^{a}$ Oxford Cardiovascular Clinical Research Facility, Division of Cardiovascular Medicine, University of Oxford, Level 1 John Radcliffe Hospital, Headley Way, Oxford, OX3 9DU, UK.

${ }^{\mathrm{b}}$ Nuffield Department of Obstetrics \& Gynaecology, University of Oxford, Level 3 Women’s Centre, John Radcliffe Hospital, Headley Way, Oxford, OX3 9DU, UK.

${ }^{\mathrm{c}}$ Centre for Statistics in Medicine, Botnar Research Centre, University of Oxford, Windmill Road, Oxford, OX3 7LD, UK.

Corresponding Author: Professor Paul Leeson, Oxford Cardiovascular Clinical Research Facility, Division of Cardiovascular Medicine, University of Oxford, John Radcliffe Hospital, Oxford. OX3 9DU. e-mail: paul.leeson@cardiov.ox.ac.uk. Tel:+44(0)1865572846, Fax:+44(0)1865572840 


\section{KEYWORDS}

Fetal, two-dimensional, echocardiography, ventricular, mass, volume, estimates, offline, semi-automated

\section{ABSTRACT}

Introduction- Two dimensional (2D) ultrasound quality has improved in recent years. Quantification of cardiac dimensions is important to screen and monitor certain fetal conditions. We assessed feasibility and reproducibility for fetal ventricular measures using 2D echocardiography, reported normal ranges from our cohort and compared estimates to other modalities.

Materials and Methods- Mass and end-diastolic volumes were estimated by manual contouring in the four-chamber view using TomTec Image Arena 4.6 in end-diastole. Nomograms were created from smoothed centiles of measures, constructed using fractional polynomials after log-transformation. Results were compared to previous studies using other modalities.

Results- 294 scans from 146 fetuses were included from $15+0$ to $41+6$ weeks gestation. $7 \%$ of scans were unanalysable and intraobserver variability was good (Intraclass Correlation Coefficients for left and right ventricular mass 0.97 (0.87-0.99) and 0.99 (0.95-1.0) respectively). Mass and volume increased exponentially showing good agreement with 3D mass estimates up to 28 weeks gestation. There was good agreement with 4D volume estimates for the left ventricle.

Discussion- Current state-of-the-art 2D echocardiography platforms provide feasible and reproducible fetal ventricular measures across gestation which appear to be in good agreement with previously published data from other datasets using newer modalities. 


\section{INTRODUCTION}

Two dimensional (2D) echocardiography has for a long time been considered the modality of choice for fetal cardiovascular imaging in the clinical setting [1]. Congenital heart disease has a reported incidence of 6 per 1000 live biths for moderate to severe forms which rises to 75 per 1000 if more mild defects are included [2]. Structural and functional defects can often have an impact on fetal cardiac dimensions including ventricular mass. Furthermore, extra-cardiac factors, such as diaphragmatic hernias, and maternal condition, for example diabetes, may also have an effect on fetal cardiac structure. Natural history data suggests certain lesions progress with reduction in ventricular size whereas other lesions may result in progressive hypertrophy. Therefore, estimation of ventricular mass for screening and monitoring purposes can aid in assessing the severity and clinical course of the condition in order to guide counselling and plan perinatal care.

In recent years, newer modalities such as 3D and 4D sonography have emerged as potentially more accurate, optional adjuncts [1]. However, this has also led to parallel improvements in 2D technology which has resulted in better image quality and development of off-line quantification packages that offer a variety of automated measures. The purpose of our study was to evaluate state-of-the-art 2D echocardiography and quantification approaches for fetal echocardiography to assess their feasibility and reproducibility. As no 2D echocardiography reference ranges exist for fetal ventricular mass and volumes, we also used the acquired data to report normal ranges from our cohort from 15 to 42 weeks gestation. Finally, we compared the values obtained against other published results using newer modalities. 


\section{MATERIALS AND METHODS}

\section{Study overview}

We acquired echocardiographic datasets on fetuses between $15+0$ and $41+6$ weeks gestation from uncomplicated, control pregnancies who were taking part in a longitudinal study - the Effect of Prematurity and hypertensive disorders of pregnancy on Offspring Cardiovascular Health (EPOCH) study (approved by South Central Berkshire Research Ethics Committee ref. 11/SC/0006, UKCRN/clinical trials ref. NCT01888770).

Gestational age was calculated based on first trimester ultrasound. Z-scores for birthweight were calculated using the International Standard size at birth reference charts from the INTERGROWTH-21 ${ }^{\text {st }}$ Project $[3,4]$ using their online application (https://intergrowth21.tghn.org/global-perinatal-package/intergrowth-21st-comparisonapplication/).

Pregnancies were excluded if the offspring showed evidence of congenital cardiovascular disease, chromosomal abnormalities or genetic disorders in the ante or postnatal period. The clinical records were also used to ensure that, for the purposes of development of fetal normal ranges, datasets from fetuses who went on to be delivered following any pregnancy complications including intrauterine growth restriction, maternal diabetes, preterm birth (before 37 weeks gestation) and/or exposure to chronic or new-onset maternal hypertension [5] were excluded from analysis.

All mothers gave written informed consent in accordance with the Declaration of Helsinki, and assent for involvement of their children, including permission to access maternal and offspring clinical records. 


\section{Echocardiography}

\section{Image Acquisition}

Each mother participated in between one and six fetal ultrasound scans during their pregnancy. Fetuses were scanned on a Philips HD9 ultrasound system with a C6-3 curved-array transducer. During image acquisition, in a period of fetal quiescence, the fetal heart had to cover at least a third of the screen using an apical or basal fourchamber view of the heart with the septum or free wall aligned parallel to the Doppler beam (plus or minus 10 degrees). Care was taken to visualise both AV valves opening and closing and the maximum diameter of both ventricles obtained. Absence of both maternal and fetal breathing and movements was also required. To enhance image resolution for post processing analysis, the frame rate was increased by minimizing the sector width, the gains and depth were optimised and multiple 7.5 second cine loops of the same four chamber view were acquired to enable offline selection of the highest quality loop. These were then retrospectively gated offline using TomTec Image Arena 4.6 where end diastole was defined at the point of mitral valve closure. Head circumference, abdominal circumference and femur length were measured according to previously published protocols with the average of three measurements being used [6]. Esimated fetal weight (EFW) was calculated using the Hadlock formula [7]. 


\section{Quantification of Ventricular Dimensions and Mass}

Left and right end diastolic volume (EDV) and ventricular mass were obtained by manual contouring of the endo and epicardium using TomTec Image Arena 4.6 from the apical four chamber view. The end diastolic frame was manually selected using the point of mitral valve closure as the marker. The contours were then manually set at the inner edge of the endocardium and the outer edge of the epicardium but within the onset of the pericardium. The mass and volumes were calculated by an algorthim built into the the package which is equivalent to the single-plane Simpson's (Figure 1). To maximise reproducibility, the entirety of the septum was contoured for both left and right ventricular measurements as in previous studies in this field [8, 9]. All datasets were analysed or the analysis directly supervised by one (CA). 10 datasets were selected at random to assess the inter and intraobserver variability in measurement of LV and RV mass (CA and RU).

\section{Statistical Analysis}

Statistical analysis was performed using SPSS Version 20, GraphPad Prism 6.0 and STATA, version 11.2, software (StataCorp LP, College Station, Texas, USA).

To create the nomograms, smoothed centiles of LV and RV mass, left and right EDV, ratio of $\mathrm{LV}$ to $\mathrm{RV}$ mass and ventricular mass as a function of EFW (i.e. ventricular mass/EFW) according to gestational age were constructed using fractional polynomials. Where appropriate, we applied a multi-level, linear regression analysis to account for repeated measures [10] but there were insignificant differences when compared to analyses that did not account for the hierarchy of the data. LV and RV mass, LV and RV EDV, ratio of LV to RV mass and ventricular mass as a function of EFW exhibited 
a non-normal distribution; therefore, the data were log-transformed (natural log) to stabilise variance and transform the data to normality. Goodness-of-fit assessment incorporated: a visual inspection of the quantile-quantile (q-q) plot of the residuals, and a plot of fitted z-scores across gestational ages.

\section{RESULTS}

\section{Study Population Characteristics}

317 fetal echocardiograms from 146 eligible fetuses without pregnancy complications who were born at term were analysed. 23 scans were unanalysable due to image quality, fetal position or movement (7\%), which left data from 294 scans to be used to build the nomograms. 91 (63\%) of the fetuses had one analysable echocardiogram, 44 (30\%) had two, 18 (12\%) had three, 10 (7\%) had four, 3 (2\%) had five and one (0.6\%) fetus had six. The range of gestational age at scan was $15+0$ to 41+6 weeks. The cohort characteristics of the fetuses contributing to the nomograms are presented in Table 1. Intraclass Correlation Coefficients (ICC) with 95\% confidence intervals for intra and inter-observer variability for measures of cardiac dimensions using TomTec Image Arena yielded 0.97 (0.87-0.99) and $0.81(0.41-0.95)$ for the left ventricular mass and $0.99(0.95-1.0)$ and $0.78(0.35-0.94)$ for the right, respectively.

\section{Cardiac mass and volume}

Normal ranges for left and right ventricular mass and end-diastolic volume are displayed in Table 2 and Figure 2 with $3^{\text {rd }}, 50^{\text {th }}$ and $97^{\text {th }}$ centiles displayed. These show that both left and right ventricular mass and EDV increase exponentially through gestation. 


\section{Patterns of mass change}

To investigate whether mass changes in proportion to cardiac volume in the fetal circulation we calculated trajectories for mass to EDV ratios for both ventricles. Mass/EDV ratios decreased slightly as pregnancy progressed from $1.7 \mathrm{~g} / \mathrm{ml}$ at 16 weeks to $1.3 \mathrm{~g} / \mathrm{ml}$ at 40 weeks and $1.7 \mathrm{~g} / \mathrm{ml}$ to $1.1 \mathrm{~g} / \mathrm{ml}$ for left and right ventricles respectively (Figure 3A). We also studied ventricular dominance in utero, and plotted RV to LV mass ratio, which increased through gestation from 0.81 at 16 weeks until term when mass in the two ventricles were equal (ratio of 1.0) (Figure 3B). Development of the fetal myocardium stayed in line with overall body growth, with the ratio of left ventricular mass to estimated fetal weight being $1 \times 10^{-3}$ at both 16 and 40 weeks and $0.8 \times 10^{-3}$ and $1.2 \times 10^{-3}$ for the right respectively (Figure 3C).

\section{Comparison to other modalities}

Previous ultrasound studies which have published normal values and/or equations for fetal ventricular mass are displayed in Table 3. Figure 4A shows trajectories reported in these papers for ventricular mass using 3D echo and real-time 3D echo [8, 11] overalaid on our 2D echo data. Real-time 3D generated values consistently greater than 3D echo by Bhat et al. [8], but there was good to excellent agreement between 2D and 3D echo for both the left and right ventricle mass up until 28 weeks gestation.

Comparison could not be made with Messing et al. for 4D ultrasound using spatio-temporal image correlation (STIC) with Virtual Organ Computer-aided AnaLysis (VOCAL) [12] as equations were not provided for mass. 
Ventricular mass estimates are derived from subtracting intraventricular from total volume and multiplying the remainder by estimated fetal myocardial density $\left(1.050 \mathrm{~g} / \mathrm{cm}^{3}\right)$ [13]. We therefore compared volume estimates from our 2D data to those available using 4D echo from two other studies (Figure 4B) [12, 14]. These figures show excellent agreement between 2D and 4D estimates for the left ventricle. Unfortunately, the published equation for the RV EDV in the Messing et al. (2007) study was incorrect and could not be plotted. The results from Hamill et al. (2011) indicate an over-estimation of right ventricular volume by 2D methods.

\section{DISCUSSION}

Normal ranges of fetal heart volumetry have been published in the past using 2D, 3D and 4D methods [8, 12, 14-20]. They all demonstrate an increase in volume over gestation but with wide variation between studies, probably as a result of the use of different methodologies. However, there has been very little published in the literature regarding estimates of mass.

\section{Previous studies}

Previous post-mortem and M-mode or 2D imaging studies have demonstrated that ventricular mass increases with gestational age and body weight [21-23]. We have shown good agreement between 2D and 3D estimates of fetal ventricular mass up to 28 weeks gestation, after which 3D estimates appear to generate values that are strikingly unrealistic, so that by 40 weeks the values are substantially greater than would be expected based on what is known about cardiac size after birth from neonatal echocardiography. This may be because estimated trajectories using real-time 3D were based on data from fetuses only up to 35 weeks gestation, at which point the estimate 
for left ventricular mass was $9.15 \mathrm{~g}$ compared to $6.07 \mathrm{~g}$ for 3D echo and our 2D estimate of 3.72g [11]. Interestingly, our 2D measures at this time point are most consistent with a previous study looking at left ventricular mass in preterm infants using cardiovascular magnetic resonance imaging which is considered the gold standard imaging modality for quantification of ventricular mass in adults [24]. This study found that mean LV mass normalized to weight at scan at a mean corrected gestational age of $34+6$ weeks was $1.39 \mathrm{~g} / \mathrm{kg}$ [25]. Bhat et al. (2004) using 3D echo also only included fetuses up to 37 weeks gestation by which time estimated LV mass was lower at $8.24 \mathrm{~g}$ but still substantially larger than the 4.31 g estimated by $2 \mathrm{D}$ echo.

There was an excellent agreement between 2D and 4D estimates for the left but not right ventricular end diastolic volumes $[12,14]$. However, our fetal RV EDV estimates at 27 weeks and 37 weeks were in good agreement with previously published measurements in preterm and term infants of similar gestations $(1.26 \mathrm{ml}$ vs $1.8 \mathrm{ml}$ at 27 weeks and $3.88 \mathrm{ml}$ vs $3.7 \mathrm{ml}$ at 37 weeks for fetal and neonatal values respectively) [26]. In addition, using similar methodology in a preterm infant in a mother with gestational diabetes and who visually had gross hypertrophy at birth which was worse in the right ventricle compared to the left, we estimated right ventricular mass as $7.86 \mathrm{~g}$ at 34 weeks gestation. This would place them above the $99^{\text {th }}$ centile on our nomogram suggesting, on this case example, validity of the ranges reported in our paper. Therefore, it will be interesting to undertake further work to compare our normal values to those from other pathological cases of severe hypertrophy or dilatation. 
Benefits of 2D echocardiographyTraditionally, transverse views are considered optimal for delineation of myocardium and estimation of mass. However, transversw views have limits in lateral resolution and fail to take into account longitudinal variation. Apical or basal views are optimal for volume estimation and the mass estimates we studied are based on endocardial and epicardial volume estimates. Out study indicates apical views can be reliably used for delineation of endo and epicardial borders for automated mass estimation using current image analysis platforms. Furthermore, failure rate for this approach are lower than previously reported in studies that have used transverse views, such as M-mode.

Other benefits of using 2D ultrasound over more novel technologies are that it is simple, faster, cheaper and more widely accessible although the Tomtec automated software may not be widely available especially in low income settings. It is still seen as the primary imaging modality for fetal echocardiography with other techniques seen as an optional adjunct [1]. In addition, newer techniques such as 3D ultrasound or 4D ultrasound using STIC requires a significant learning period both for acquisition and analysis $[8,12,14]$. They also involve either manually defining the contours serially at each plane (4D with STIC) [12] or tracing along endo and epicardial surfaces (3D) [8] both of which are significantly more time consuming that extraction of data from $2 \mathrm{D}$ echocardiograms. There are limitations to newer methods, such as inability to perform measurements at extremes of gestation $[12,20]$ and reliance on the fetus being in a optimum position with a significant period of quiescence $[12,14,20]$ as well as acoustic shadowing and dropout $[14,20]$. This results in up to a sixth of scans being unsuitable for analysis [8]. However, this is not an isolated problem with newer technologies; a previous study using M-mode to describe ventricular geometry and function reported a 
rejection rate of $21 \%$, much higher than $7 \%$ in our study [27]. Finally, even though our acquisition was not gated, measurements could be timed for end diastole by offline gating using mitral valve closure unlike 3D ultrasound where the four chamber view can often only be analysed in mid-diastole [8].Limitations

2D methods have previously been criticized as they have been shown to have a high level of interobserver variability compared to 3D and 4D methods especially for the fetal right ventricle $[8,12]$. We found, however, that using our newer quantification package for analysis both inter and in particular intraobserver variability was low. In addition, there was some variability in what was considered normal mass and volume from our 2D assessment throughout gestation and it has been reported that in some cases of pathology, the use of $2 \mathrm{D}$ for volume measurements can underestimate the severity of the diagnosis [12]. Furthermore, our automated technique was based on algorithms that were developed for the adult left ventricle and therefore some assumptions may be inaccurate in our cohort due to geometrical and maturation differences in the fetus. This may also explain our results from the right ventricle as we would have expected right ventricular dominance especially in later pregnancy. It may be that due to different right and left ventricular geometries the estimation of mass using our algorithm make it difficult to compare directly absolute values between left and right ventricles. However, this does not preclude using this modality as a screening tool where newer technologies are available, especially if serial measurements are taken by the same operator.

Another potential limitation of our study was that we did not provide validation against an inanimate or animal model for our measures of mass. We also did not have access to $2 \mathrm{D}$ and 3 or $4 \mathrm{D}$ estimates from the same individual, so direct comparison of 
methodologies could not be performed. This may have been useful as we were using a 2D single-plane method which may have resulted in inaccuracies due to geometrical assumptions. Single-plane methods using 2D ultrasound have previously been used in studies where estimation of volumes and mass have been technically challenging [28, 29] such as the left atrium in adults demonstrating strong correlation with bi-plane measures [30] and the right ventricle in neonates [29] showing good agreement with angiography [31]. It is important to note that fetal echocardiography requires technical skill and even then, biplane views are not always feasible. Therefore the requirement for only a four chamber view, which can usually be visualised in the majority fetuses by 13 weeks gestation [32, 33], makes this method for determination of mass widely applicable.

This study suggests that current state-of-the-art 2D echocardiography ultrasound platforms and off-line analysis software provides feasible and reproducible measures that appear to be in good agreement expected ranges generated by newer methodologies up to 28 weeks gestation. Our technique allows estimation of fetal ventricular mass in a wide range of gestations and is likely to be of value across a range of healthcare settings. We have also reported, for the first time, fetal normal ranges of ventricular mass using 2D echo from our cohort between $15+0$ to $41+6$ weeks gestation. Further work using our technique in a larger cohort with and increased number of measures within each gestational week would allow these nomograms to start to be used in clinical practice. We believe that in certain circumstances such as extremes of gestation, 2D ultrasound may be the modality of choice in the clinical setting, and at other times provide a screening or monitoring test, after which other novel modalities may be used as adjuncts. 



\section{ACKNOWLEDGMENTS}

We are grateful to all the women and babies who took part in this study. This work was supported by grants to Professor Paul Leeson from the British Heart Foundation (FS/06/024 and FS/11/65/28865).

\section{CONFLICTS OF INTEREST}

The authors declare no conflicts of interest. 


\section{REFERENCES}

1. American Institute of Ultrasound in $M$, AIUM practice guideline for the performance of fetal echocardiography. J Ultrasound Med, 2013. 32(6): p. 1067-82.

2. Hoffman JI and Kaplan S, The incidence of congenital heart disease. J Am Coll Cardiol, 2002. 39(12): p. 1890-900.

3. Villar J, Ismail LC, Victora CG, Ohuma EO, Bertino E, Altman DG, Lambert A, Papageorghiou AT, Carvalho M, Jaffer YA, Gravett MG, Purwar M, Frederick IO, Noble AJ, Pang RY, Barros FC, Chumlea C, Bhutta ZA, Kennedy SH, and Growth IFN, International standards for newborn weight, length, and head circumference by gestational age and sex: the Newborn Cross-Sectional Study of the INTERGROWTH21st Project. Lancet, 2014. 384(9946): p. 857-868.

4. Villar J, Giuliani F, Fenton TR, Ohuma EO, Ismail LC, Kennedy SH, and Consortium I-s, INTERGROWTH-21st very preterm size at birth reference charts. Lancet, 2016. 387(10021): p. 844-845.

5. Brown MA, Lindheimer MD, de Swiet M, Van Assche A, and Moutquin JM, The classification and diagnosis of the hypertensive disorders of pregnancy: statement from the International Society for the Study of Hypertension in Pregnancy (ISSHP). Hypertens Pregnancy, 2001. 20(1): p. IX-XIV.

6. Papageorghiou AT, Ohuma EO, Altman DG, Todros T, Cheikh Ismail L, Lambert A, Jaffer YA, Bertino E, Gravett MG, Purwar M, Noble JA, Pang R, Victora CG, Barros FC, Carvalho M, Salomon LJ, Bhutta ZA, Kennedy SH, Villar J, International F, and Newborn Growth Consortium for the 21st C, International standards for fetal growth based on serial ultrasound measurements: the Fetal Growth Longitudinal Study of the INTERGROWTH-21st Project. Lancet, 2014. 384(9946): p. 869-79.

7. Hadlock FP, Harrist RB, Sharman RS, Deter RL, and Park SK, Estimation of fetal weight with the use of head, body, and femur measurements--a prospective study. Am J Obstet Gynecol, 1985. 151(3): p. 333-7.

8. Bhat AH, Corbett V, Carpenter N, Liu N, Liu R, Wu A, Hopkins G, Sohaey R, Winkler C, Sahn CS, Sovinsky V, Li X, and Sahn DJ, Fetal ventricular mass determination on threedimensional echocardiography: studies in normal fetuses and validation experiments. Circulation, 2004. 110(9): p. 1054-60.

9. Messing B, Cohen SM, Valsky DV, Shen O, Rosenak D, Lipschuetz M, and Yagel S, Fetal heart ventricular mass obtained by STIC acquisition combined with inversion mode and VOCAL. Ultrasound Obstet Gynecol, 2011. 38(2): p. 191-7.

10. Group WMGRS, Assessment of differences in linear growth among populations in the WHO Multicentre Growth Reference Study. Acta Paediatr Suppl, 2006. 450: p. 56-65.

11. Zheng M, Schaal M, Chen Y, Li X, Shentu W, Zhang P, Ashraf M, Ge S, and Sahn DJ, Real-time 3-dimensional echocardiographic assessment of ventricular volume, mass, and function in human fetuses. PLoS One, 2013. 8(3): p. e58494.

12. Messing B, Cohen SM, Valsky DV, Rosenak D, Hochner-Celnikier D, Savchev S, and Yagel $S$, Fetal cardiac ventricle volumetry in the second half of gestation assessed by 4D ultrasound using STIC combined with inversion mode. Ultrasound Obstet Gynecol, 2007. 30(2): p. 142-51.

13. Myerson SG, Montgomery HE, World MJ, and Pennell DJ, Left ventricular mass: reliability of $\mathrm{M}$-mode and 2-dimensional echocardiographic formulas. Hypertension, 2002. 40(5): p. 673-8.

14. Hamill N, Yeo L, Romero R, Hassan SS, Myers SA, Mittal P, Kusanovic JP, Balasubramaniam M, Chaiworapongsa T, Vaisbuch E, Espinoza J, Gotsch F, Goncalves 
$\mathrm{LF}$, and Lee W, Fetal cardiac ventricular volume, cardiac output, and ejection fraction determined with 4-dimensional ultrasound using spatiotemporal image correlation and virtual organ computer-aided analysis. Am J Obstet Gynecol, 2011. 205(1): p. 76 e1-10.

15. Schmidt KG, Silverman NH, and Hoffman Jl, Determination of ventricular volumes in human fetal hearts by two-dimensional echocardiography. Am J Cardiol, 1995. 76(17): p. 1313-16.

16. Chang FM, Hsu KF, Ko HC, Yao BL, Chang CH, Yu CH, Liang RI, and Chen HY, Fetal heart volume assessment by three-dimensional ultrasound. Ultrasound Obstet Gynecol, 1997. 9(1): p. 42-8.

17. Meyer-Wittkopf M, Cole A, Cooper SG, Schmidt S, and Sholler GF, Three-dimensional quantitative echocardiographic assessment of ventricular volume in healthy human fetuses and in fetuses with congenital heart disease. J Ultrasound Med, 2001. 20(4): p. 317-27.

18. Mielke $\mathrm{G}$ and Benda N, Cardiac output and central distribution of blood flow in the human fetus. Circulation, 2001. 103(12): p. 1662-8.

19. Esh-Broder E, Ushakov FB, Imbar T, and Yagel S, Application of free-hand threedimensional echocardiography in the evaluation of fetal cardiac ejection fraction: a preliminary study. Ultrasound Obstet Gynecol, 2004. 23(6): p. 546-51.

20. Uittenbogaard LB, Haak MC, Spreeuwenberg MD, and van Vugt JM, Fetal cardiac function assessed with four-dimensional ultrasound imaging using spatiotemporal image correlation. Ultrasound Obstet Gynecol, 2009. 33(3): p. 272-81.

21. St John Sutton MG, Raichlen JS, Reichek N, and Huff DS, Quantitative assessment of right and left ventricular growth in the human fetal heart: a pathoanatomic study. Circulation, 1984. 70(6): p. 935-41.

22. St John Sutton MG, Gewitz MH, Shah B, Cohen A, Reichek N, Gabbe S, and Huff DS, Quantitative assessment of growth and function of the cardiac chambers in the normal human fetus: a prospective longitudinal echocardiographic study. Circulation, 1984. 69(4): p. 645-54.

23. Zheng $X Z$, Yang $B$, and $W u J$, Fetal left ventricular mass determination on 2dimensional echocardiography using area-length calculation methods. J Ultrasound Med, 2014. 33(2): p. 349-54.

24. Grothues F, Smith GC, Moon JC, Bellenger NG, Collins P, Klein HU, and Pennell DJ, Comparison of interstudy reproducibility of cardiovascular magnetic resonance with two-dimensional echocardiography in normal subjects and in patients with heart failure or left ventricular hypertrophy. Am J Cardiol, 2002. 90(1): p. 29-34.

25. Broadhouse KM, Finnemore AE, Price AN, Durighel G, Cox DJ, Edwards AD, Hajnal JV, and Groves AM, Cardiovascular magnetic resonance of cardiac function and myocardial mass in preterm infants: a preliminary study of the impact of patent ductus arteriosus. J Cardiovasc Magn Reson, 2014. 16: p. 54.

26. Levy PT, Dioneda B, Holland MR, Sekarski TJ, Lee CK, Mathur A, Cade WT, Cahill AG, Hamvas A, and Singh GK, Right ventricular function in preterm and term neonates: reference values for right ventricle areas and fractional area of change. J Am Soc Echocardiogr, 2015. 28(5): p. 559-69.

27. Wladimiroff JW, Vosters R, and McGhie JS, Normal cardiac ventricular geometry and function during the last trimester of pregnancy and early neonatal period. Br J Obstet Gynaecol, 1982. 89(10): p. 839-44.

28. Hudsmith LE, Petersen SE, Francis JM, Robson MD, and Neubauer S, Normal human left and right ventricular and left atrial dimensions using steady state free precession magnetic resonance imaging. J Cardiovasc Magn Reson, 2005. 7(5): p. 775-82. 
29. Ichihashi K, Ewert P, Welmitz $G$, and Lange $P$, Changes in ventricular and muscle volumes of neonates. Pediatr Int, 1999. 41(1): p. 8-12.

30. Russo C, Hahn RT, Jin Z, Homma S, Sacco RL, and Di Tullio MR, Comparison of echocardiographic single-plane versus biplane method in the assessment of left atrial volume and validation by real time three-dimensional echocardiography. J Am Soc Echocardiogr, 2010. 23(9): p. 954-60.

31. Jin Z SH, Kampmann C et al., Echocardiographic right ventricular volumes and mass in normal children and those with atrial setpal deects pre and post closure. Cardiol. Young, 1993. 3 (Suppl. 1): p. 141.

32. Gembruch $U$, Shi $C$, and Smrcek JM, Biometry of the fetal heart between 10 and 17 weeks of gestation. Fetal Diagn Ther, 2000. 15(1): p. 20-31.

33. Levental M, Pretorius DH, Sklansky MS, Budorick NE, Nelson TR, and Lou K, Threedimensional ultrasonography of normal fetal heart: comparison with two-dimensional imaging. J Ultrasound Med, 1998. 17(6): p. 341-8. 
Table 1: Fetal Cohort Characteristics

$n=146$

Maternal Demographics \& Anthropometrics

Age at delivery, years

$31.3 \pm 4.5$

BMI at booking, $\mathrm{kg} / \mathrm{m}^{2}$

$23.8 \pm 3.8$

Smokers, n (\%)

$16(11)$

Offspring Demographics \& Anthropometrics

Gestational age, weeks

$39.9 \pm 1.3$

Males, n (\%)

$80(55)$

Birth order

$1 \pm 1$

Caesarean section, n (\%)

$23(16)$

Birthweight, grams

$3423 \pm 445$

Birthweight Z-score

$0.29 \pm 0.9$

Values as Mean \pm Standard Deviation unless stated otherwise

* Median \pm Interquartile range 
Table 2a: Normal Range for Fetal Ventricular Mass

\begin{tabular}{lcccccc}
\hline & \multicolumn{3}{c}{ LV Mass (g) } & & \multicolumn{3}{c}{ RV Mass (g) } \\
Week & \multicolumn{2}{c}{} & & & \\
& $\mathrm{P}_{3}$ & $\mathrm{P}_{50}$ & $\mathrm{P}_{97}$ & $\mathrm{P}_{3}$ & $\mathrm{P}_{50}$ & $\mathrm{P}_{97}$ \\
\hline 16 & 0.07 & 0.15 & 0.34 & 0.06 & 0.11 & 0.23 \\
18 & 0.13 & 0.29 & 0.65 & 0.12 & 0.23 & 0.46 \\
20 & 0.22 & 0.49 & 1.07 & 0.21 & 0.41 & 0.82 \\
22 & 0.35 & 0.75 & 1.62 & 0.33 & 0.66 & 1.31 \\
24 & 0.51 & 1.08 & 2.27 & 0.49 & 0.97 & 1.93 \\
26 & 0.70 & 1.46 & 3.02 & 0.68 & 1.35 & 2.68 \\
28 & 0.93 & 1.89 & 3.84 & 0.90 & 1.79 & 3.56 \\
30 & 1.19 & 2.37 & 4.71 & 1.16 & 2.29 & 4.55 \\
32 & 1.48 & 2.89 & 5.63 & 1.43 & 2.84 & 5.63 \\
34 & 1.80 & 3.44 & 6.56 & 1.73 & 3.43 & 6.80 \\
36 & 2.14 & 4.01 & 7.51 & 2.04 & 4.06 & 8.05 \\
38 & 2.51 & 4.61 & 8.45 & 2.38 & 4.71 & 9.35 \\
40 & 2.90 & 5.22 & 9.38 & 2.72 & 5.39 & 10.70 \\
42 & 3.31 & 5.84 & 10.30 & 3.07 & 6.10 & 12.10 \\
\hline
\end{tabular}

LV mass: $\mathrm{P}_{3}=\exp \left(4.020472+\left(-9.473844 *(\mathrm{GA} / 10)^{\wedge}-1\right)+(-1.88 *(.526187+(-.0053485 *(\mathrm{GA}))))\right) . \mathrm{P}_{50}=$ $\exp \left(4.020472+\left(-9.473844 *(\mathrm{GA} / 10)^{\wedge}-1\right)\right) . \mathrm{P}_{97}=\exp \left(4.020472+\left(-9.473844 *(\mathrm{GA} / 10)^{\wedge}-1\right)+(1.88 *(.526187+(-\right.$ $.0053485 *(\mathrm{GA})))))$

RV mass: $\mathrm{P}_{3}=\exp \left(4.253648+\left(-10.2729 *(\mathrm{GA} / 10)^{\wedge}-1\right)+(-1.88 *(0.3644328))\right) \cdot \mathrm{P}_{50}=\exp (4.253648+(-$ $\left.\left.10.2729 *(\mathrm{GA} / 10)^{\wedge}-1\right)\right) \cdot \mathrm{P}_{97}=\exp \left(4.253648+\left(-10.2729 *(\mathrm{GA} / 10)^{\wedge}-1\right)+(1.88 *(0.3644328))\right)$

Table 2b: Normal Range for Fetal Ventricular Volume

\section{EDV (ml) $\quad$ RV EDV (ml)}

\begin{tabular}{lcccccc} 
Week & $\mathrm{P}_{3}$ & $\mathrm{P}_{50}$ & $\mathrm{P}_{97}$ & $\mathrm{P}_{3}$ & $\mathrm{P}_{50}$ & $\mathrm{P}_{97}$ \\
\hline 16 & 0.04 & 0.08 & 0.16 & 0.03 & 0.07 & 0.20 \\
18 & 0.09 & 0.17 & 0.33 & 0.06 & 0.16 & 0.40 \\
20 & 0.15 & 0.30 & 0.59 & 0.12 & 0.29 & 0.71 \\
22 & 0.24 & 0.47 & 0.94 & 0.21 & 0.49 & 1.12 \\
24 & 0.35 & 0.70 & 1.38 & 0.34 & 0.75 & 1.66 \\
26 & 0.49 & 0.97 & 1.92 & 0.50 & 1.08 & 2.31 \\
28 & 0.65 & 1.29 & 2.54 & 0.70 & 1.46 & 3.08 \\
30 & 0.83 & 1.65 & 3.25 & 0.93 & 1.91 & 3.95 \\
32 & 1.03 & 2.04 & 4.02 & 1.19 & 2.42 & 4.92 \\
34 & 1.25 & 2.46 & 4.86 & 1.48 & 2.97 & 5.97 \\
36 & 1.47 & 2.91 & 5.74 & 1.79 & 3.57 & 7.10 \\
38 & 1.71 & 3.38 & 6.67 & 2.13 & 4.21 & 8.30 \\
40 & 1.96 & 3.87 & 7.64 & 2.49 & 4.88 & 9.55 \\
42 & 2.21 & 4.37 & 8.63 & 2.87 & 5.58 & 10.85 \\
\hline
\end{tabular}

LV EDV: $\mathrm{P}_{3}=\exp \left(3.917406+\left(-10.25886 *(\mathrm{GA} / 10)^{\wedge}-1\right)+(-1.88 *(0.3618528))\right) \cdot \mathrm{P}_{50}=\exp (3.917406+(-$ $\left.\left.10.25886 *(\mathrm{GA} / 10)^{\wedge}-1\right)\right) . \mathrm{P}_{97}=\exp \left(3.917406+\left(-10.25886 *(\mathrm{GA} / 10)^{\wedge}-1\right)+(1.88 *(0.3618528))\right)$

RV EDV: $\mathrm{P}_{3}=\exp \left(4.39255+\left(-11.23125 *(\mathrm{GA} / 10)^{\wedge}-1\right)+\left(-1.88 *\left(0.3213458+0.5765573 *(\mathrm{GA} / 10)^{\wedge}-2\right)\right)\right) \cdot \mathrm{P}_{50}=$ $\exp \left(4.39255+\left(-11.23125 *(\mathrm{GA} / 10)^{\wedge}-1\right)\right) \cdot \mathrm{P}_{97}=\exp \left(4.39255+\left(-11.23125 *(\mathrm{GA} / 10)^{\wedge}-1\right)+(1.88 *(0.3213458+\right.$ $\left.\left.\left.0.5765573 *(G A / 10)^{\wedge}-2\right)\right)\right) L V$ indicates left ventricular; RV right ventricular; EDV end-diastolic volume; $P$ percentile; GA gestational age in weeks 
Table 3: Comparison of the present study to previously published studies

\begin{tabular}{|c|c|c|c|c|c|c|}
\hline Authors & Year & Modality & $\begin{array}{c}\text { No. of } \\
\text { datasets }\end{array}$ & $\begin{array}{c}\text { Range of } \\
\text { gestation } \\
\text { (weeks) }\end{array}$ & $\begin{array}{c}\text { Structural } \\
\text { ventricular } \\
\text { parameters measured }\end{array}$ & $\begin{array}{c}\text { Unanalysable } \\
\text { datasets, } \\
\text { n (\%) }\end{array}$ \\
\hline Current Study & & $2 \mathrm{D}$ & 317 & $15.0-41.7$ & $\begin{array}{l}\mathrm{LV} \text { and RV mass } \\
\mathrm{LV} \text { and RV EDV }\end{array}$ & $23(7 \%)$ \\
\hline St John Sutton et al.* & 1983 & M-mode & 78 & $20.0-38.0$ & $\begin{array}{l}\text { LV mass } \\
\text { LV and RV diastolic } \\
\text { \& systolic diameters } \\
\text { Septal \& free wall } \\
\text { thicknesses }\end{array}$ & $2(2.6 \%)$ \\
\hline Bhat et al. & 2004 & $3 \mathrm{D}$ & 90 & $15.5-37.0$ & LV and RV mass & $15(17 \%)$ \\
\hline Messing et al.* & 2011 & $\begin{array}{l}\text { 3D STIC + } \\
\text { VOCAL }\end{array}$ & 121 & $21.0-38.0$ & LV and RV mass & $15(12 \%)$ \\
\hline Zheng et al. & 2013 & Real-time 3D & 59 & $16.7-34.6$ & $\begin{array}{l}\mathrm{LV} \text { and RV mass } \\
\mathrm{LV} \text { and RV EDV } \\
\mathrm{LV} \text { and RV ESV }\end{array}$ & $7(12 \%)$ \\
\hline
\end{tabular}

LV indicates left ventricular; RV right ventricular; 3D three dimensional; STIC spatiotemporal image correlation; VOCAL Virtual Organ Computer-aided Analysis; EDV end-diastolic volume; ESV end-systolic volume; 2D two dimensional.

*No equation/table of normal values provided by study 

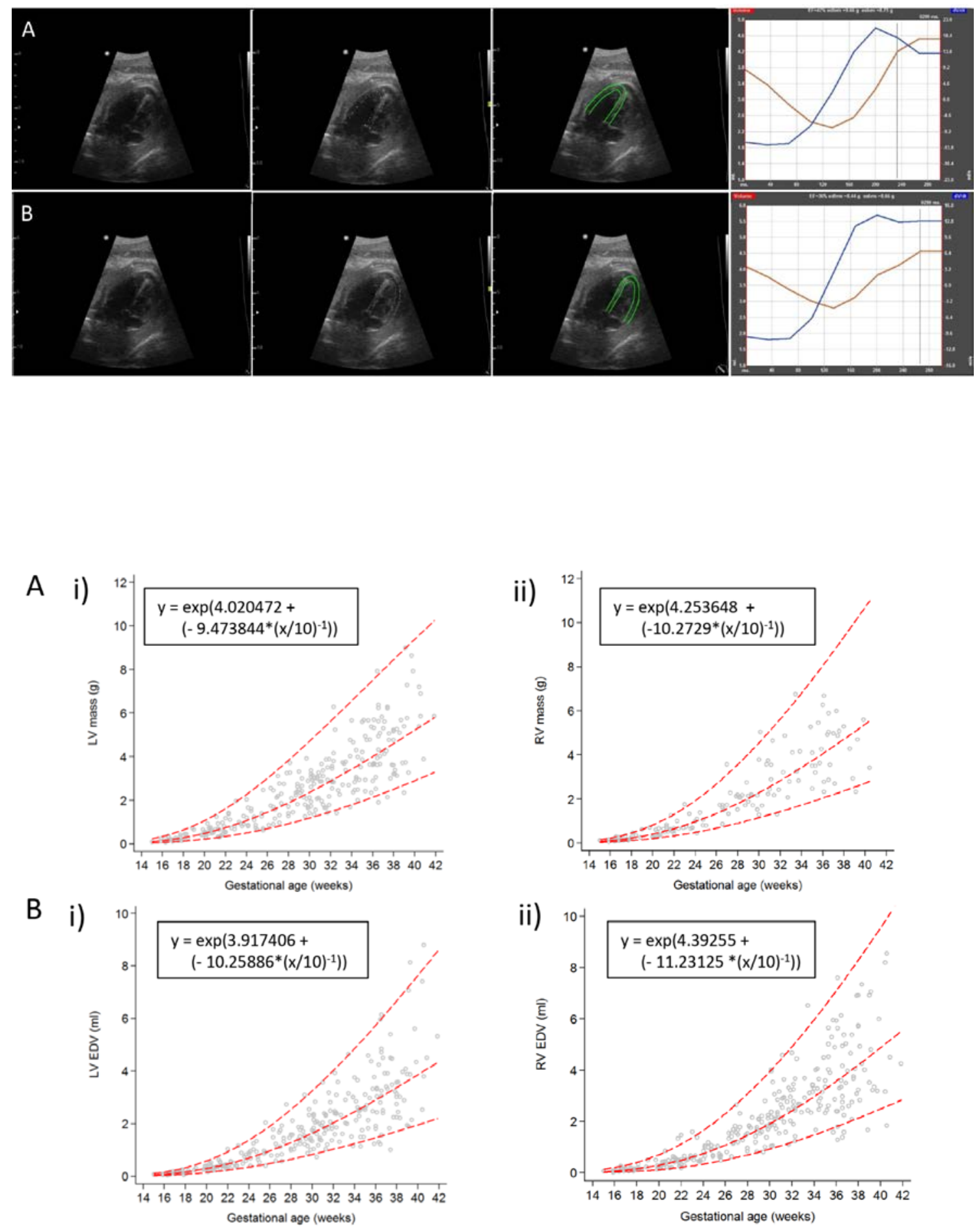
A

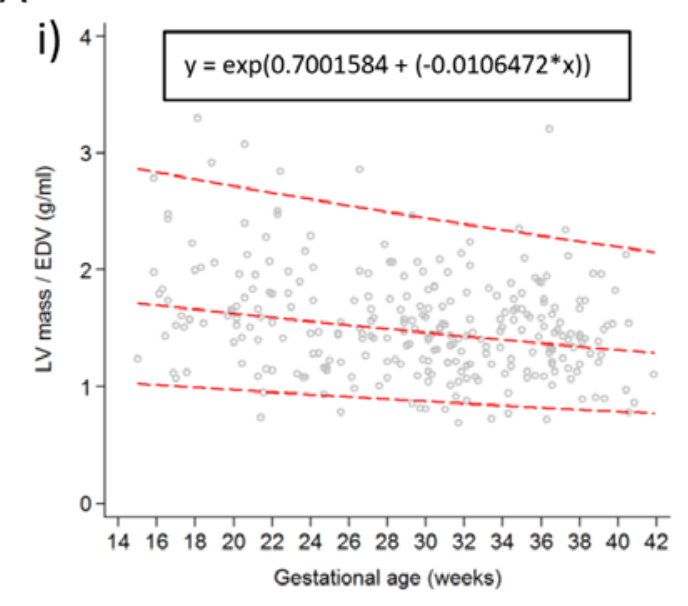

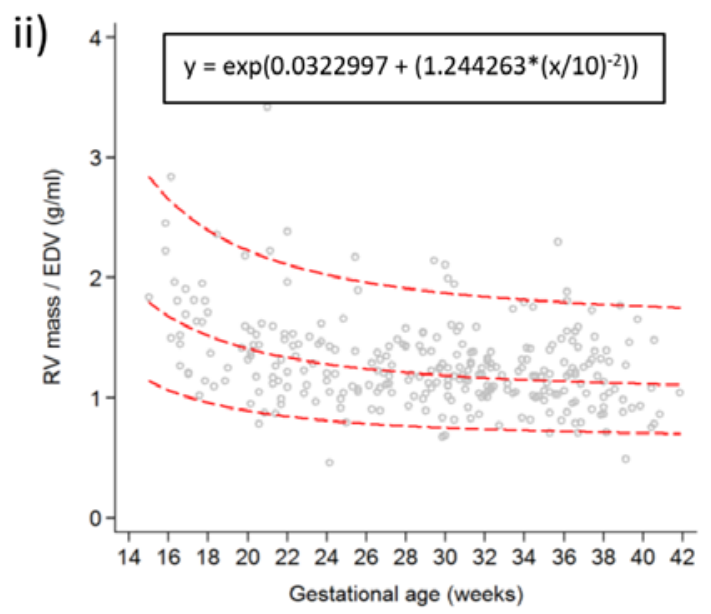

B

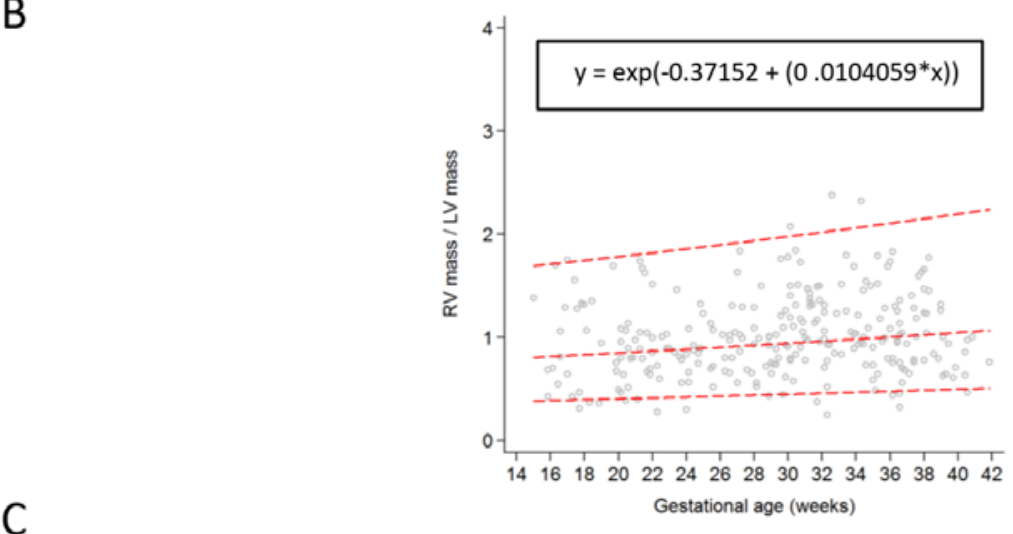

C
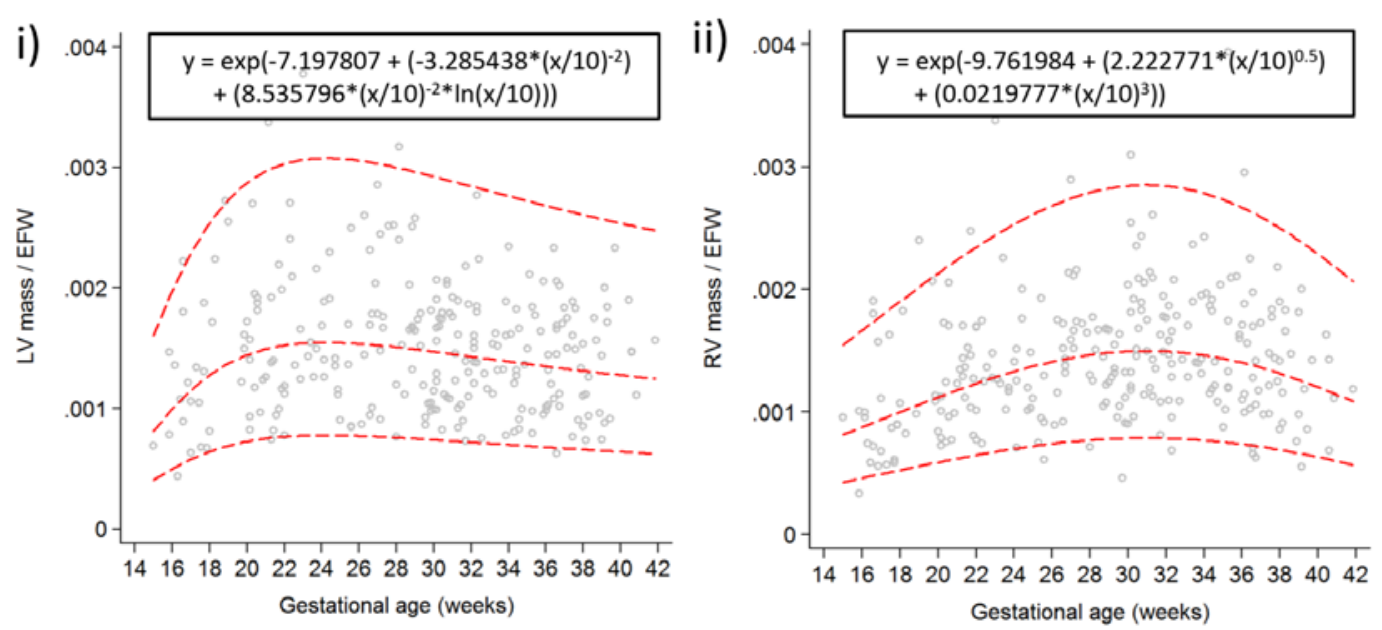
A

i)

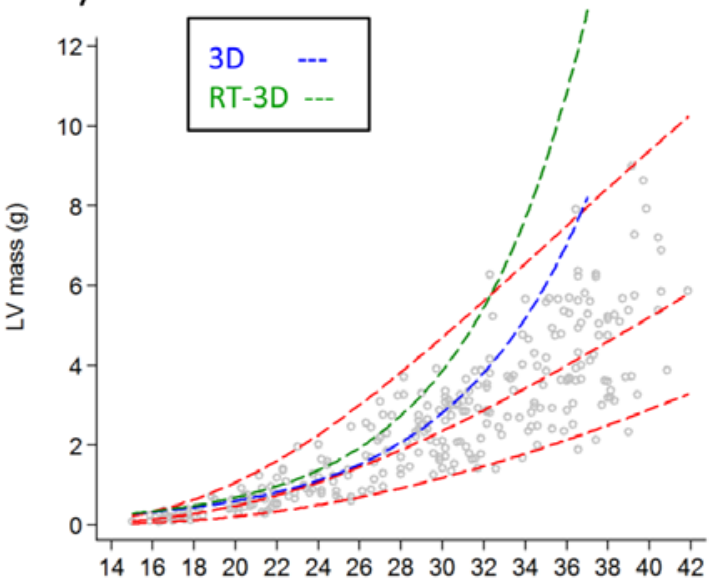

B

i)

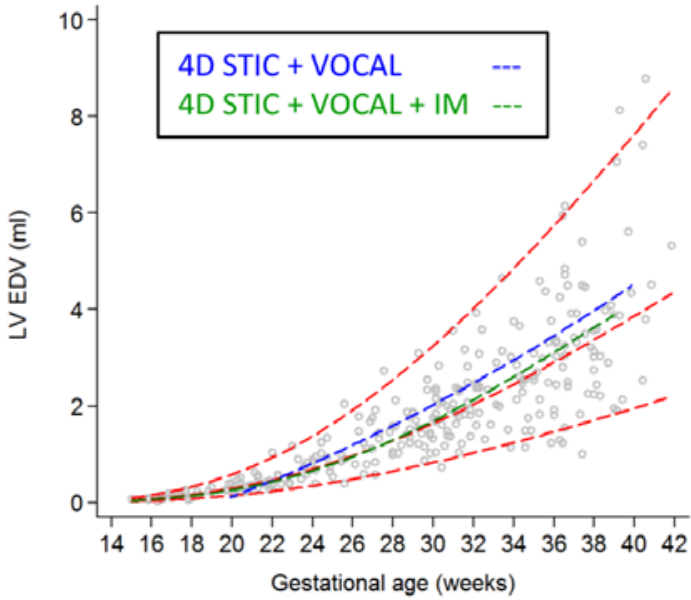

ii)

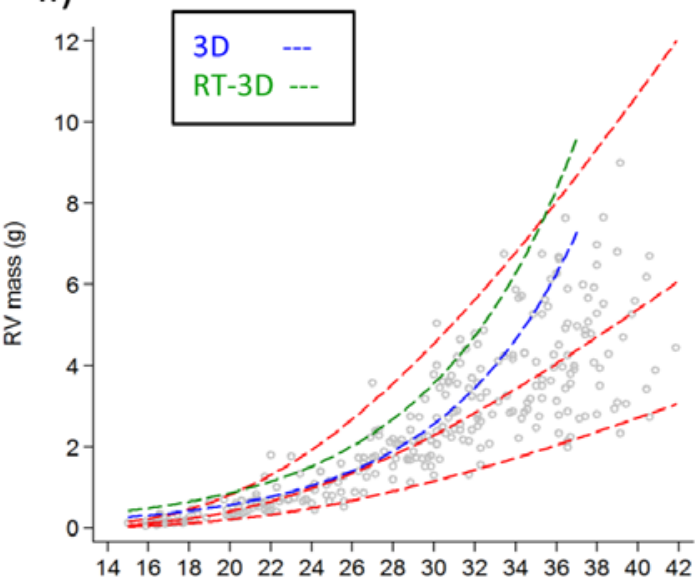

ii)

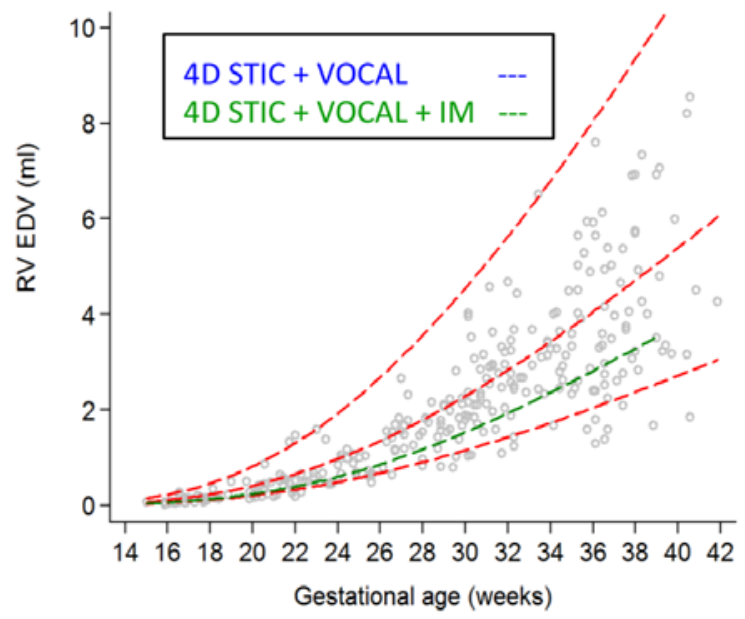

